\title{
Predictors of mortality in patients with prosthetic valve infective endocarditis: A nation-wide multicenter study
}

\author{
Mehmet Ali Elbey ${ }^{1}$, Mehmet Emin Kalkan², Serkan Akdag ${ }^{3}$, Kerem Ozbek ${ }^{4}$, \\ Nihan Kahya Eren ${ }^{5}$, Sinan Demirtas ${ }^{6}$, Mehmet Ata Akil $^{1}$, Selim Topcu ${ }^{7}$, \\ Mustafa Oylumlu ${ }^{1}$, Zihni Bilik ${ }^{1}$, Murat Yuksel ${ }^{1}$ \\ ${ }^{1}$ Dicle University School of Medicine, Department of Cardiology. Diyarbakır, Turkey \\ ${ }^{2}$ Kartal Kosuyolu Education and Research Hospital, Clinical Cardiology, Istanbul, Turkey \\ ${ }^{3}$ Yuzuncu Y1l University School of Medicine, Department of Cardiology, Van, Turkey \\ ${ }^{4}$ Gaziosman Pasa University School of Medicine, Department of Cardiology, Tokat, Turkey \\ ${ }^{5}$ Izmir Ataturk Education and Research Hospital, Clinical Cardiology, Izmir, Turkey \\ ${ }^{6}$ Dicle University School of Medicine, Department Cardiovascular Surgery, Diyarbakır, Turkey \\ ${ }^{7}$ Ataturk University School of Medicine, Department of Cardiology, Erzurum, Turkey
}

\begin{abstract}
Background: Our aim was to investigate the clinical and prognostic features of the patients with prosthetic valve endocarditis (PVE) in a multicenter nation-wide study.

Methods: The present nation-wide study consisted of 75 consecutive patients with PVE treated at 13 major hospitals in Turkey from 2005 to 2012.

Results: The patients who died during follow-up were significantly older than the survivors and had higher C-reactive protein (CRP), creatinine, poor NYHA functional class and large vegetations. High creatinine level (odds ratio [OR] 2.6, 95\% confidence interval [CI] 1.14-6.13), poor functional status (OR 24.5; 95\% CI 3.1-196.5) and high CRP (OR 1.02; 95\% CI 1.00-1.03) measured on admission were independent risk associates for in-hospital mortality Conclusions: High creatinine level, poor functional status and high CRP measured on admission were independent risk associates for in-hospital mortality, whereas a NYHA class of III/IV and high CRP reflected independent risk for stroke/mortality end point. (Cardiol J 2013; 20, 3: 323-328)
\end{abstract}

Key words: infective endocarditis, mortality, prognostic factors

\section{Introduction}

Infective endocarditis is a life-threatening serious condition, despite of the major advances made in diagnosis, treatment and management $[1,2]$. Prosthetic valve endocarditis (PVE) remains a diagnostic challenge, with non-specific and variable clinical symptoms and cardiac conditions. Treatment options include prolonged antibiotic therapy, repair of prosthetic valve and repeat valve replacement in complicated cases [3-6]. PVE not only carries a high in-hospital mortality risk but also is associated with high long term mortality and needs close follow up.

Address for correspondence: Mehmet Ali Elbey, MD, Dicle University, School of Medicine, Department of Cardiology, 21280 Diyarbakır, Turkey, tel: +90 041224880 01, fax: +90 041224885 23, e-mail: elbeymali@hotmail.com

Received: $15.08 .2012 \quad$ Accepted: 27.11.2012 
Most of the data on clinical outcomes of PVE come from western countries $[7,8]$ and there is a lack of data in Turkey regarding nation-wide multicenter experience. Therefore our aim was to investigate the etiology and risk factors for PVE and identify clinical, echocardiographic and prognostic features of the patients with PVE and determine the risk factors for adverse outcome during hospital admission in Turkey.

\section{Methods}

The present nation-wide study consisted of 75 consecutive patients with PVE treated at 13 major tertiary referral centers from 2005 to 2012 in all geographical regions of Turkey. The following data were recorded for each patient: age, sex, predisposing heart disease, presenting signs and symptoms, results of laboratory and microbiological investigations, echocardiographic findings, involved valve, treatment modality and in hospital outcomes. The diagnosis of definite PVE was confirmed using the modified Duke's criteria [9]. All hospitals are tertiary referral centers, which receive patients from surrounding hospitals. Complete blood count, C-reactive protein (CRP), erythrocyte sedimentation rates, serum chemistry, and urine analysis, the antibiotic regimen, aspects related to the surgical approach and in-hospital outcome were also recorded.

The study was approved by the local Medical Ethics Committee.

\section{Definitions}

Early PVE was defined as the diagnosis of PVE within 60 days of valve surgery, whereas late PVE was the diagnosis of PVE beyond 60 days after surgery. Hospital mortality was defined as death occurring during the initial hospitalization for PVE. Fever was defined as body temperature $>38.3^{\circ} \mathrm{C}$. Embolic events were defined as clinical or radiographic evidence of cerebral or peripheral involvement (limbs, spleen, kidneys, lungs or mix).

\section{Statistical analysis}

Statistical Package for Social Sciences software (SPSS 12, Chicago, IL, USA) was used for analysis. Descriptive parameters were shown as mean \pm standard deviation (SD) or in percentages. Student's t-test was used to compare continuous variables. Categorical data were compared with $\chi^{2}$ test. Abnormally distributed variables were compared using Mann-Whitney U test. Multivariate logistic regression analysis was used to assess the independent risks for in-hospital mortality and major adverse outcome (mortality or disabling stroke). The covariates included in the analysis were age, white blood cell, creatinine, heart rate, vegetation size and poor NYHA functional class on admission (class III or IV). A p value of $<0.05$ was considered significant.

\section{Results}

The mean age of the patients was $46 \pm 18$ (range 14-87). Forty seven (63\%) patients were male. Of the 75 PVE patients, 26 died during hospital follow-up. Mortality rate was $35 \%$. Sixteen patients experienced a stroke and 14 of them died which showed a very high rate of in-hospital mortality (88\%). Clinical, echocardiographic and microbiological variables of survivors and patients who died were compared in Tables 1 and 2. The patients who died during follow-up were significantly older than the survivors and had higher mean heart rate, white blood cell, CRP, creatinine, poor NYHA functional class, aortic regurgitation and large vegetations.

A pathogenic microorganism was isolated from blood cultures in 50 (68\%) cases. Staphylococci were the most common causative organisms (25\%), followed by streptococci, which were identified in $13 \%$ of cases. Community-acquired methicillin-resistant S. aureus was found in $4(5 \%)$ patients and coagulase-negative staphylococci in $5 \%$. The next most common etiologic agents were enterococci $(11 \%)$. Culture-negative endocarditis occurred in $24(32 \%)$ patients.

Mean duration of hospital stay was $30 \pm 19$ days. All patients received combination antibiotic therapy for 4 to 6 weeks. The most common antibiotics used were penicillin, ceftriaxon, vancomycin, aminoglycoside, rifampicin, meropenem and sulperazon. Valve surgery was required in 30 (40\%) patients during index hospitalization. The main indication for surgery was refractory heart failure, persistent large vegetation, prosthesis dysfunction and persistent infection. Treatment with valve surgery was not significantly associated with a better hospital outcome. Among the $45(60 \%)$ patients who received medical therapy alone, hospital mortality was 33\%. Among the patients who had treated with surgery, 11 died (mortality rate was $37 \%$ ).

In order to understand independent risks for mortality and major adverse events logistic regression analysis was performed. Creatinine, CRP and poor NYHA class on admission were independent risks for mortality and CRP and poor NYHA class 
Table 1. Comparison of baseline demographic and clinical characteristics on admission.

\begin{tabular}{lccc}
\hline & $\begin{array}{c}\text { Survivors } \\
(\mathbf{n}=\mathbf{4 9 )}\end{array}$ & $\begin{array}{c}\text { Patients who died during } \\
\text { follow-up } \mathbf{n}=\mathbf{2 6})\end{array}$ & $\mathbf{P}$ \\
\hline Age [years] & $44 \pm 14$ & $53 \pm 17$ & $\mathbf{0 . 0 1 5}$ \\
Gender: Female & $15(31 \%)$ & $13(50 \%)$ & 0.099 \\
Patient history: & & & \\
$\quad$ Chronic renal failure & $\mathbf{5 ( 1 0 \% )}$ & $\mathbf{1 0}(\mathbf{3 8} \%)$ & $\mathbf{0 . 0 0 4}$ \\
Diabetes mellitus & $6(12 \%)$ & $3(11 \%)$ & 0.929 \\
Weight loss & $3(6 \%)$ & $5(19 \%)$ & 0.08 \\
Fever $\left.>38.3^{\circ} \mathrm{C}\right)$ & $40(82 \%)$ & $17(65 \%)$ & 0.117 \\
Systolic blood pressure [mm Hg] & $114 \pm 13$ & $107 \pm 17$ & 0.063 \\
Diastolic blood pressure [mm Hg] & $70 \pm 10$ & $68 \pm 9$ & 0.526 \\
Pulse [bpm] & $86 \pm 13$ & $95 \pm 15$ & $\mathbf{0 . 0 1 1}$ \\
Hemoglobin [g/dL] & $11.3 \pm 1.9$ & $11 \pm 1.3$ & 0.625 \\
White blood cell [n/mL] & $14426 \pm 7641$ & $18340 \pm 7487$ & $\mathbf{0 . 0 3 7}$ \\
Sedimentation rate [mm/h] & $66 \pm 25$ & $69 \pm 34$ & 0.591 \\
C-reactive protein [mg/dL] & $59 \pm 46$ & $109 \pm 91$ & $\mathbf{0 . 0 0 2}$ \\
Creatinine [mg/dL] & $1.1 \pm 0.6$ & $1.5 \pm 0.9$ & $\mathbf{0 . 0 1 1}$ \\
NYHA $>$ 2 & $15(31 \%)$ & $23(91 \%)$ & $<0.001$ \\
Septic shock & $1(2 \%)$ & $10(38 \%)$ & $<\mathbf{0 . 0 0 1}$ \\
Stroke & $2(4 \%)$ & $14(54 \%)$ & $<0.001$ \\
Embolism & $4(8 \%)$ & $8(31 \%)$ & $\mathbf{0 . 0 1 1}$ \\
Atrial fibrillation & $15(31 \%)$ & $4(15 \%)$ & 0.149 \\
Atrioventricular block & $3(6 \%)$ & $2(8 \%)$ & 0.797 \\
\hline
\end{tabular}

Continuous variables were represented as mean \pm SD

Table 2. Comparison of echocardiographic and microbiological variables in patients with prosthetic valve endocarditis (PVE) survivors and patients died during hospital follow-up.

\begin{tabular}{lccc}
\hline & $\begin{array}{c}\text { Survivors } \\
(\mathbf{n}=49)\end{array}$ & $\begin{array}{c}\text { Patients who died during } \\
\text { follow-up (n = 26) }\end{array}$ & P \\
\hline Vegetations: & & & \\
$\quad$ Multiple & $8(16 \%)$ & $7(27 \%)$ & 0.275 \\
$\quad$ Mobile & $28(57 \%$ & $17(65 \%)$ & 0.488 \\
$\quad$ Diameter (> 10 mm) & $13(26 \%)$ & $14(54 \%)$ & $\mathbf{0 . 0 0 2}$ \\
Aortic regurgitation & $2(4 \%)$ & $10(38 \%)$ & $\mathbf{0 . 0 0 1}$ \\
Mitral regurgitation & $3(6 \%)$ & $3(11 \%)$ & 0.848 \\
Dehiscence & $5(10 \%)$ & $6(23 \%)$ & 0.134 \\
Ejection fraction & $51 \pm 11$ & $49 \pm 10$ & 0.461 \\
Staphylococcus aureus & $10(20 \%)$ & $6(23 \%)$ & 0.788 \\
Enterococci & $5(10 \%)$ & $6(23 \%)$ & 0.134 \\
Streptococcus viridans & $0(0 \%)$ & $6(12 \%)$ & 0.065 \\
Coagulase-negative staphylococci & $5(10 \%)$ & $2(8 \%)$ & 0.724 \\
Culture negative & $17(39 \%)$ & $9(35 \%)$ & 0.995 \\
Early PVE & $3(6 \%)$ & $4(15 \%)$ & 0.192 \\
Late PVE & $45(92 \%)$ & $20(77 \%)$ & 0.071 \\
Mitral PVE & $25(51 \%)$ & $11(42 \%)$ & 0.472 \\
Aortic PVE & $18(37 \%)$ & $10(38 \%)$ & 0.883 \\
Mitral + aortic PVE & $5(10 \%)$ & $4(15 \%)$ & 0.511 \\
Surgical treatment & $19(39 \%)$ & $11(42 \%)$ & 0.766 \\
\hline
\end{tabular}

Continuous variables were represented as mean $\pm \mathrm{SD}$ 
Table 3. Multivariate logistic regression analysis assessing the independent risks for in-hospital mortality and major adverse outcome (stroke or mortality).

\begin{tabular}{lccccccc}
\hline Variables & \multicolumn{3}{c}{ Model for mortality } & & & Model for stroke or mortality \\
\cline { 2 - 3 } & $\begin{array}{c}\text { Odds } \\
\text { ratio }\end{array}$ & $\begin{array}{c}\text { 95\% confidence } \\
\text { interval }\end{array}$ & $\mathbf{P}$ & & $\begin{array}{c}\text { Odds } \\
\text { ratio }\end{array}$ & $\begin{array}{c}\text { 95\% confidence } \\
\text { interval }\end{array}$ & $\mathbf{P}$ \\
\hline Age & 1.048 & $0.992-1.106$ & 0.95 & & 1.047 & $0.988-1.098$ & 0.126 \\
White blood cell & 1.000 & $1.000-1.000$ & 0.254 & & 1.000 & $1.000-1.000$ & 0.483 \\
Creatinine & 2.643 & $1.139-6.133$ & $\mathbf{0 . 0 2 4}$ & & 2.026 & $0.906-4.530$ & 0.085 \\
C-reactive protein & 1.017 & $1.003-1.031$ & 0.017 & & 1.013 & $1.001-1.025$ & $\mathbf{0 . 0 3 5}$ \\
Heart rate & 1.021 & $0.973-1.073$ & 0.396 & & 1.027 & $0.978-1.079$ & 0.280 \\
Vegetation size & 2.595 & $0.516-13.049$ & 0.247 & & 4.678 & $1.000-21.888$ & 0.050 \\
NYHA > 2 & 24.53 & $3.06-196.508$ & $\mathbf{0 . 0 0 3}$ & & 14.04 & $2.490-79.168$ & $\mathbf{0 . 0 0 3}$ \\
\hline
\end{tabular}

on admission were independent risks for major adverse events; poor NYHA class being the most powerful risk factor for both (Table 3 ).

\section{Discussion}

To the best of our knowledge, this is the first multicenter study investigating the clinical characteristics, prognostic features and outcomes of Turkish patients with PVE. The results of the current study showed that PVE was associated with high overall in-hospital mortality (35\%). Despite improvements in diagnosis, medical treatment and surgery, PVE carries a high mortality risk ranging from $20-80 \%$ of affected patients [10-15]. In general, combined medical and surgical treatment is considered the management of choice in patients with PVE.

For patients with PVE the best treatment strategy is still controversial because guidelines based on prospective randomized trials are lacking $[4,16$, 17]. Numerous studies indicate that the prognosis of patients with PVE is better using a combined medical-surgical approach than when antibiotic treatment alone is used $[15,18]$. In the present study, more than half of our patients were treated with antibiotic therapy alone, and only $67 \%$ of them survived. On the other hand, 30 patients underwent valve surgery and $63 \%$ of them survived. Surgical treatment for PVE is complex and involves high mortality, between $15 \%$ and $64 \%$ according to different series $[15,19]$. In some patients with PVE, severe complications clearly require urgent surgical treatment but only few investigators have analyzed which patients can be treated safely by antibiotics alone [20]. PVE is a complex disease and its outcome is influenced by many factors such as the disease itself, characteristics of the patient, and surgical results $[21,22]$. So the treatment of PVE should be individualized.

In our study, several factors were found to be associated with hospital mortality by logistic analysis (NYHA $>2$, creatinine level and CRP). In a retrospective study that was carried out on 46 patients with left-sided prosthetic valve endocarditis who needed urgent surgery, fever at admission, persistent infection, positive blood cultures, persistently positive cultures, and echocardiographic evidence of vegetations were associated with a poor prognosis [23]. Presence of an abscess at echocardiography, urgent surgical treatment, heart failure, thrombocytopenia, and renal failure were significant predictors of in-hospital death in a single-centre study conducted retrospectively on 133 patients [24]. In a multicenter, international registry including 367 patients with PVE, $42 \%$ of the patients had undergone surgical treatment and in-hospital mortality was similar for patients treated with surgery compared with those treated with medical therapy alone $(25.0 \%$ vs. $23.4 \%, \mathrm{p}=$ $=0.729$ [ [25]. A possible explanation to this finding is that more complicated patients had been treated with surgery. Surgical therapy was independently associated with patient age, microorganism, intracardiac abscess, and congestive heart failure. It is clear that PVE carries a high in-hospital mortality risk and subgroups of patients should be identified for whom surgery is associated with a better outcome. Patients with staphylococcal infection, complicated PVE and brain embolism were independently associated with a trend toward a survival benefit $[10,25]$. This data is completely concordant with our study. Surgical therapy did not show a survival benefit in our patient cohort possibly due to the selection of complicated cases. Deprived renal 
function and poor functional status are well known risks for mortality. Serial measurement of CRP on the other hand, was shown to be an independent predictor of poor outcome for patients with CRP levels in the highest tertile [26].

Another important finding of our study is the high rate of stroke and its association with high mortality rate. Cerebral emboli in endocarditis generally result from dislodgment or fragmentation of cardiac vegetations, followed by vessel occlusion; this results in various degrees of ischemia and infarction, depending on the vessels and the collateral blood flow. A recently published study showed that, among 198 patients with definite left-sided infective endocarditis, 55\% experienced at least one neurologic complication, ischemic stroke and cerebral hemorrhage being the most frequent [27].

\section{Conclusions}

PVE was associated with high overall in-hospital mortality. High creatinine level, poor functional status and high CRP measured on admission were independent risk associates for in-hospital mortality, whereas a NYHA class of III/IV and high CRP reflected independent risk for stroke/mortality end point. Poor functional class had the highest odds ratio for both.

\section{Acknowledgements}

Collaborator list in alphabetical order: 1. Ataturk University School of Medicine, Department of Cardiology, Erzurum, Turkey (Enbiya Aksakal, Selim Topcu); 2. Bulent Ecevit University School of Medicine, Department of Cardiology, Zonguldak, Turkey (Mustafa Aydin, M. Rasit Sayin); 3. Cumhuriyet University School of Medicine, Department of Cardiology, Sivas, Turkey (Hekim Karapinar, Zekeriya Kucukdurmaz); 4. Dicle University School of Medicine, Department of Cardiology, Diyarbakır, Turkey (Siddik Ulgen, Sait Alan, Serdar Soydinc, Yahya Islamoglu, Zuhal Ariturk, Ebru Onturk, Habib Cil, Faruk Ertas, Mesut Aydın, Umit Inci, Abdurrahman Akyuz); 5. Duzce University School of Medicine, Department of Cardiology, Duzce, Turkey (Ismail Ekinozu, Yusuf Aslantas); 6. Erciyes University School of Medicine, Department of Cardiology, Kayseri, Turkey (Mehmet G. Kaya, Mahmut Akpek); 7. Eskisehir Osmangazi University School of Medicine, Department of Cardiology, Eskisehir, Turkey (Taner Ulus); 8. Gaziosman Pasa University School of Medicine, Department of Cardiology, Tokat, Turkey (Fatih Koc, Kerem Ozbek); 9. Kahramanmaras Sutcu Imam University School of Medicine, Department of Cardiology, Kahramanmaras, Turkey (Cemal Tuncer, Gurkan Acar); 10. Kartal Kosuyolu Education and Research Hospital, Clinical Cardiology, Istanbul, Turkey (Ali Metin Esen); 11. Izmir Ataturk Education and Research Hospital, Clinical Cardiology, Izmir, Turkey (Oktay Ergene, Nihan Kahya Eren); 12. Suleyman Demirel University School of Medicine, Department of Cardiology, Isparta, Turkey (Abdullah Dogan, Fatih Kahraman); 13. Yuzuncu Yil University School of Medicine, Department of Cardiology, Van, Turkey (Serkan Akdag)

Conflict of interest: none declared

\section{References}

1. Murdoch DR, Corey GR, Hoen B et al. Clinical presentation, etiology, and outcome of infective endocarditis in the $21^{\text {st }}$ century: The International Collaboration on Endocarditis-Prospective Cohort Study. Arch Intern Med, 2009; 169: 463-473.

2. Tleyjeh IM, Steckelberg JM, Murad HS et al. Temporal trends in infective endocarditis: A population-based study in Olmsted County, Minnesota. JAMA, 2005; 293: 3022-3028.

3. Piper C, Korfer R, Horstkotte D. Prosthetic valve endocarditis. Heart, 2001; 85: 590-593.

4. Hee-Hwa H, Chung-Wah S, Kai-Hang Y, Hung-Fat T, Wing-Hung C, Wing-Hing C. Prosthetic valve endocarditis in a multicenter registry of Chinese patients. Asian Cardiovasc Thorac Ann, 2010; 18: 430-434.

5. Wang A, Athan E, Pappas PA et al. Contemporary clinical profile and outcome of prosthetic valve endocarditis. JAMA, 2007; 297: 1354-1361.

6. Castillo JC, Anguita MP, Torres F et al. Long-term prognosis of early and late prosthetic valve endocarditis. Am J Cardiol, 2004; 93: 1185-1187.

7. Horstkotte D, Korfer R, Loogen F, Rosin H, Bircks W. Prosthetic valve endocarditis: clinical findings and management. Eur Heart J, 1984; 5: 117-122.

8. Akowuah EF, Davies W, Oliver S et al. Prosthetic valve endocarditis: Early and late outcome following medical or surgical treatment. Heart, 2003; 89: 269-272.

9. Li JS, Sexton DJ, Mick N et al. Proposed modifications to the Duke criteria for the diagnosis of infective endocarditis. Clin Infect Dis, 2000; 30: 633-638.

10. Habib G, Tribouilloy C, Thuny F et al. Prosthetic valve endocarditis: who needs surgery? A multicentre study of 104 cases. Heart, 2005; 91: 954-959.

11. Calderwood SB, Swinski LA, Karchmer AW, Waternaux CM, Buckley MJ. Prosthetic valve endocarditis. Analysis of factors affecting outcome of therapy. J Thorac Cardiovasc Surg, 1986; 92: 776-783.

12. Tornos P, Almirante B, Olona $\mathrm{M}$ et al. Clinical outcome and long-term prognosis of late prosthetic valve endocarditis: A 20-year experience. Clin Infect Dis, 1997; 24: 381-386.

13. Wolff M, Witchitz S, Chastang C, Regnier B, Vachon F. Prosthetic valve endocarditis in the ICU. Prognostic factors of overall survival in a series of 122 cases and consequences for treatment decision. Chest, 1995; 108: 688-694. 
14. Akowuah EF, Davies W, Oliver S et al. Prosthetic valve endocarditis: Early and late outcome following medical or surgical treatment. Heart, 2003; 89: 269-272.

15. John MD, Hibberd PL, Karchmer AW, Sleeper LA, Calderwood SB. Staphylococcus aureus prosthetic valve endocarditis: Optimal management and risk factors for death. Clin Infect Dis, 1998; 26: 1302-1309.

16. ACC/AHA 2006 Guidelines for the Management of Patients With Valvular Heart Disease: Executive Summary A Report of the American College of Cardiology/American Heart Association Task Force on Practice Guidelines (Writing Committee to Revise the 1998 Guidelines for the Management of Patients With Valvular Heart Disease). Circulation, 2006; 114: 450-527.

17. Baddour LM, Wilson WR, Bayer AS et al. Infective endocarditis: diagnosis, antimicrobial therapy and management of complications: A statement for healthcare professionals from the Committee on Rheumatic Fever, Endocarditis, and Kawasaki Disease, Council on Cardiovascular Disease in the Young, and the Councils on Clinical Cardiology, Stroke, and Cardiovascular Surgery and Anesthesia, American Heart Association: Endorsed by the Infectious Diseases Society of America. Circulation, 2005; 111: 394-434.

18. Revilla A, López J, Sevilla T et al. In-hospital prognosis of prosthetic valve endocarditis after urgent surgery. Rev Esp Cardiol, 2009; 62: 1388-1394.

19. Grünenfelder J, Akins CW, Hilgenberg $\mathrm{AD}$ et al. Long-term results and determinants of mortality after surgery for native and prosthetic valve endocarditis. J Heart Valve Dis, 2001; 10: 694-702.

20. Hill EE, Herijgers P, Claus P, Vanderschueren S, Herregods MC, Peetermans WE. Infective endocarditis: Changing epidemiology and predictors of 6-month mortality: A prospective cohort study. Eur Heart J, 2007; 28: 196-203.

21. Piehler JM, Blackstone EH, Bailey KR et al. Reoperation on prosthetic heart valves. Patient specific estimates of hospital events. J Thorac Cardiovasc Surg, 1995; 109: 30-48.

22. $\mathrm{Oz}$ BS, Iyem H, Akay HT et al. Risk factors for short- and long-term survival in patients undergoing re-replacement due toprosthetic valve dysfunction. Heart Vessels, 2006; 21: 339-343 .

23. Revilla A, López J, Sevilla T et al. In-hospital prognosis of prosthetic valve endocarditis after urgent surgery. Rev Esp Cardiol, 2009; 62: 1388-1394.

24. Alonso-Valle H, Farinas-Alvarez C, García-Palomo JD et al. Clinical course and predictors of death in prosthetic valve endocarditis over a 20-year period. J Thorac Cardiovasc Surg, 2010; 139: 887-893.

25. Wang A, Pappas P, Anstrom KJ et al. International Collaboration on Endocarditis Investigators. The use and effect of surgical therapy for prosthetic valve infective endocarditis: A propensity analysis of a multicenter, international cohort. Am Heart J, 2005; 150: 1086-1091.

26. Verhagen DW, Hermanides J, Korevaar JC et al. Prognostic value of serial C-reactive protein measurements in left-sided native valve endocarditis. Arch Intern Med, 2008; 168: 302-307.

27. Sonneville R, Mirabel M, Hajage D et al. ENDOcardite en REAnimation Study Group. Neurologic complications and outcomes of infective endocarditis in critically ill patients: The ENDOcardite en REAnimation prospective multicenter study. Crit Care Med, 2011; 39: 1474-1481. 